University of Wollongong

Research Online

Faculty of Engineering and Information

Faculty of Engineering and Information

Sciences - Papers: Part A

Sciences

2013

Inter-organisational knowledge sharing in regional sustainable development communities

Rosemary Van Der Meer

University of Wollongong, rvdmeer@uow.edu.au

Luba Torlina

Deakin University

Jamie Mustard

Deakin University

Follow this and additional works at: https://ro.uow.edu.au/eispapers

Part of the Engineering Commons, and the Science and Technology Studies Commons

Research Online is the open access institutional repository for the University of Wollongong. For further information contact the UOW Library: research-pubs@uow.edu.au 


\title{
Inter-organisational knowledge sharing in regional sustainable development communities
}

\author{
Abstract \\ There has been an increasing interest in the use of inter-organisational groups to address regional \\ implications in sustainable development. These groups bring together local knowledge and expertise and \\ span boundaries between government and industry organisations. Our focus is in understanding how \\ knowledge is shared in such inter-organisational groups. Utilising interviews, observations and social \\ network analysis, we examine the knowledge sharing implications derived from the mixed membership, \\ multilevel interaction, and the need to span boundaries with external organisations in these \\ collaborations.
}

\section{Keywords}

sharing, knowledge, organisational, regional, inter, communities, sustainable, development

Disciplines

Engineering | Science and Technology Studies

\section{Publication Details}

Van Der Meer, R., Torlina, L. \& Mustard, J. (2013). Inter-organisational knowledge sharing in regional sustainable development communities. International Journal of Technology Management, 12 (3/4), 252-272. 


\title{
Inter-organisational knowledge sharing in regional sustainable development communities
}

\author{
Rosemary Van Der Meer* \\ School of Information Systems, \\ Faculty of Business \& Law, \\ Deakin University, \\ Geelong, Victoria, Australia, 3220 \\ E-mail: rosemary.vandermeer@deakin.edu.au \\ *Corresponding author
}

\section{Luba Torlina}

School of Information Systems,

Faculty of Business \& Law,

Deakin University,

Burwood, Victoria, Australia, 3125

E-mail: luba.torlina@ deakin.edu.au

\section{Jamie Mustard}

School of Information Systems,

Faculty of Business \& Law,

Deakin University,

Geelong, Victoria, Australia, 3220

E-mail: jamie.mustard@deakin.edu.au

\begin{abstract}
There has been an increasing interest in the use of interorganisational groups to address regional implications in sustainable development. These groups bring together local knowledge and expertise and span boundaries between government and industry organisations. Our focus is in understanding how knowledge is shared in such inter-organisational groups. Utilising interviews, observations and social network analysis, we examine the knowledge sharing implications derived from the mixed membership, multilevel interaction, and the need to span boundaries with external organisations in these collaborations.
\end{abstract}

Keywords: inter-organisational; knowledge sharing; sustainable development; regional knowledge communities

Biographical Notes: Rosemary Van Der Meer holds an MTECH. (Business Systems Design and Management) from Swinburne University of Technology and is currently pursuing her $\mathrm{PhD}$ in knowledge sharing and sustainable development at Deakin University. Rosemary teaches in the areas of information systems, eBusiness infrastructure and project management. She has previously taught in China and worked in the semiconductor industry in The Netherlands. 


\begin{abstract}
Author
Dr Luba Torlina is a senior lecturer in the School of Information Systems, Faculty of Business and Law, Deakin University. She has $\mathrm{PhD}$ from the Institute for System Studies, Moscow. During her career Dr Torlina has held several positions in academia as well as in industry. In Australia, before joining Deakin University, her teaching and research experience was with Monash and Melbourne Universities. Dr Torlina's publications are in the areas of information product quality, information markets, knowledge management and organisational learning. Her current research includes projects on communities of practice in public services, and knowledge sharing in sustainable development.

Dr Jamie Mustard is the Deputy Head of the School of Information Systems at Deakin University. He has a broad range of research interests including applied statistics, eLearning, and knowledge management. He currently teaches in the areas of information systems and statistics at both the undergraduate and postgraduate level.
\end{abstract}

\title{
1 Introduction
}

Regional sustainable development groups have become more prevalent in recent years due to the growing concerns with regards to climate change. These sustainable development groups bring together a mix of government and industry members to examine sustainable development issues that affect the region. These issues can include climate change adaptation, biodiversity and urban planning across local government borders. The groups collaborate to develop policies and practical applications on sustainable development that meet regional needs.

These groups bring a local focus to the issues with local knowledge and expertise. They can cross boundaries between business and government offering opportunities for collaboration on projects, foster the sharing of knowledge and broaden the understanding and views of those organisations involved (von Malmborg 2003).

At the same time, joint collaboration at the regional level brings about a number of difficulties in transferring knowledge and establishing co-operation. These groups include mixed membership between multiple government, business, non-profit and educational organisations with potentially differing agendas that can be more complicated than found in other inter-organisational groups. Groups that focus on regional sustainable development need to address economic, social and environmental issues as well as governmental political agendas. This means that members can have a greater difficulty developing a mutual understanding, a key requirement in successful knowledge sharing (Cohen \& Levinthal 1990; Lawson et al. 2009). Furthermore, knowledge developed by the group needs to cross boundaries from the group to multiple external bodies (Carlile 2004). Such boundary crossing to differing external bodies requires group strategies to allow successful knowledge transfer.

In this study we aim at developing a better understanding of knowledge sharing in such inter-organisational groups. The research question at the core of this study is:

- How knowledge is shared in inter-organisational groups that focus on regional sustainable development? 
In order to answer this question, the paper examines in detail a regional, sustainable development group made up of industry and government members. More specific questions related to the context of our study include:

- How knowledge sharing occurs within the group?

- How the broad knowledge domain can influence knowledge sharing?

- How the need to span boundaries between the group and external organisations impacts knowledge sharing?

A case study research has been conducted, with data collected via questionnaires, observations and in-depth interviews. The analysis included investigation of knowledge networks within the group, group structure and activities, and the ways the group deals with the issues of multiple agendas, multiple knowledge bases of mixed membership, and the need to transfer knowledge to participating organisations.

The rest of the paper is structured as follows. Section 2 outlines the literature on government-industry collaboration in sustainable development and the issues with knowledge sharing in these partnerships. Section 3 describes the methodological approach to the research including outlining the case study group and research design utilised. Section 4 reports on the results found and section 5 summarises the implications of these findings with regards to the research question and future directions of the research.

\section{Issues of Knowledge Sharing in Inter-organisational Regional Sustainable Development: Literature review}

A regional perspective is very important for sustainable development. Individuals, organisations and communities may independently appreciate and practice values of sustainable development. However, real substantial outcomes can be achieved only when all those efforts are coordinated and based on a shared vision of the region as an integral natural ecosystem and human built environment. A successful triple bottom line approach where economic success for business enterprises can be created by meeting environmental and social objectives (Manring \& Moore 2006) largely depends on creating and managing effective collaborative partnerships among the stakeholders, their commitment to a shared vision, and a deliberate effort to build a broad-based, long-term support among constituency (Manring et al. 2003).

The response of these issues has been the development of inter-organisational groups that combine the resources and knowledge of both government and business organisations within a region (Martinuzzi et al. 2000; Sedlacek \& Gaube 2010; Shearlock et al. 2000; von Malmborg 2003). These groups are well positioned to recognise regional needs for sustainability and develop practical applications to address those needs. Their key advantage is that actors are embedded in the regional context and have specific knowledge of the issues that are important to the region (Sedlacek \& Gaube 2010).

The issues of knowledge communication in regional industry-government interorganisational collaboration are described in section 2.1. The challenges of sharing knowledge in government-industry collaborations are reviewed in section 2.2. The templates for industry-government sustainable collaboration, as discussed in the literature, are outlined in section 2.3. 


\section{Author}

\subsection{Knowledge sharing in industry-government sustainable development groups}

Paquette and Wiseman (2006) highlight industry-government collaboration as an opportunity for wider access to knowledge and ideas from sources that are beyond the participating individual organisations boundaries. Having broader membership allows members of industry-government groups to explore different ways of thinking about the environmental issues they confront (Manring et al. 2003). This is in contrast to the boundaries and constraints the individuals face within their own organisations such as business interests and budgetary responsibilities (Manring et al. 2003; Manring \& Moore 2006).

Additionally, members are able to embrace the bigger picture of the region, rather than just the specific issue faced by their individual organisations. By being able to examine the complexities of the regional impacts and the options available, an interorganisational group are able to make decisions that include informed social and environmental considerations while maintaining economic improvement. A good example of this occurred in the Monroe 2020 project, where a problem with sceneryobscuring billboards was overcome through a combined examination across the whole of the region that allowed for continued signage without obscuring the scenery along highways (Manring et al. 2003).

A number of studies have highlighted that knowledge sharing between members of a regional inter-organisational network often occurs at several levels. The top level involves full group participation. Interaction at this level provides opportunities to bring together all the members to share knowledge from outside experts (Sanders 2001), collaboratively address and resolve mutual issues with regards to sustainable development (Manring \& Moore 2006) and provide an opportunity for face-to-face interaction that can aid in building trust between members and network development for individual knowledge sharing (Manring et al. 2003). In some networks this top level may not have a strong operational focus, but it is a means to organise and develop working groups to deal with specific issues as occurred in the Monroe 2020 group examined by Manring et al. (2003). The second or middle level involves the formation of projectdriven or issue-driven sub-groups between particular members in response to needs and opportunities and these sub-groups only last as long as the purpose they serve (Manring $\&$ Pearsall 2006). The third or lowest level involves informal linkages between individual members that evolve as they attempt to understand and clarify particular issues (Manring \& Pearsall 2006).

Manring and Moore (2006) describe the example of knowledge sharing in such a multilevel network in the case of a textile industry sustainable development network. The network was 'bubbling' with small groups, clusters and coalitions focusing on their specialist aspects of the overall toxicity problem. These sub-groups, or bubbles of concentrated knowledge sharing, formed the middle level of the network and they "knew little about the intricacies of each other's operations and did not trust each other" (p894). However, by being part of the whole network level, they were able to make connections to information sources, and retain those sources and the links as long as needed. Another good example of how multiple levels affects knowledge sharing is given in a study on informal network negotiations between biotech firms. Tang (2008) found that executives regard informal knowledge transfer (i.e. at the lower level) as the key to determining which organisations to develop formal contractual agreements with. 


\subsection{Challenges for knowledge sharing in industry-government collaboration}

Industry-government collaborations on sustainable development, while providing potential for effective knowledge sharing, are also faced with some complexities that are reflected in the knowledge sharing literature.

One of the issues faced by industry-government collaborations involve the different and sometimes competing views of members due to the broad mix of membership with different knowledge bases, thought worlds and priorities of the organisations they represent (Lindkvist 2005; Grabher 2003). While the need to develop a shared understanding of sustainable development is vital (von Malmborg 2003), and a mutual understanding is essential for effective knowledge sharing collaborations (Cohen \& Levinthal 1990; Lawson et al. 2009; van den Hooff et al. 2003), in practice achieving consensus may be difficult and may require tailored knowledge sharing approaches (Grabher 2003).

Inter-organisational regional collaborations need to deal with high complexity of the knowledge sharing process and a broader range of stakeholders contributing to the knowledge sharing (Hartley \& Bennington 2006). Industry participants are generally focused on economic gains (Gravier et al. 2008; Heiman \& Nickerson 2002; Lawson et al. 2009; Levy et al. 2003; Wagner \& Bukó 2005). While industry members may have a social or environmental reason for participating, they still factor economic improvement as key in sustainable development implementation (von Malmborg 2003). In contrast, governmental participants may include economic agendas but the main focus is generally on the social aspect for the community and region.

Further, these inter-organisational groups need to communicate knowledge not only across boundaries between different members within the group, but also between the group and external organisations. Carlile (2004) classified such inter-organisational knowledge sharing as crossing syntactic, semantic and pragmatic boundaries.

The syntactic boundary involves the development of a "common lexicon" (Carlile 2004, p558). As an inter-organisational group involving members from government and industry, the use of terminology can differ and requires the development of a mutual language to aid in understanding and knowledge transfer between the members from the different organisations.

The semantic boundary deals with the consideration of differing agendas and perspectives. Government and industry perspectives on issues such as climate change, carbon taxes and the economic issues behind sustainable development adaptation can be very different. The aim of the group is to create shared meanings by interpretation of organisational perspectives on a group level

The pragmatic boundary recognises the differences in practices of the actors involved in knowledge development. There may be consequences of knowledge transfer or the need to adapt the knowledge for transfer (Carlile 2004). These consequences or need for adaptation of the knowledge can generate additional costs that must be considered in the knowledge transfer process and timeframes.

Industry-government groups on sustainable development must deal with the political issues of the government members. The changing political aspects of government can add a high level of uncertainty to the relationship (Hartley \& Bennington 2006). Regional inter-organisational groups need to meet local political agendas to ensure the successful uptake and application of knowledge provided by the group to external government 
bodies. This requires consideration of how knowledge should be represented and also when it should be presented to the external government organisations.

In summary, the key aspects for knowledge sharing in an industry-government sustainable inter-organisational group include having a wide focus that includes regional environmental, economic and social aspects, a broad knowledge domain and wide access to knowledge due to the mixed membership, a high level of complexity with both governmental and industry agendas affecting knowledge sharing, the need to transfer knowledge across differing boundaries both within the group and externally and a level of uncertainty due to the political aspects of the governmental members.

\section{3 (Governance) Templates for industry-government sustainable development collaboration}

Inter-organisational collaboration may adopt different governance structures, which consequently affect the way knowledge is shared. The extant literature describes several different templates for inter-organisational industry-government sustainable development groups. von Malmborg (2003) describes three templates for sustainable development partnerships examined in Europe while Manring et al. (2003) describe a fourth template utilised in a number of sustainable development projects in the USA.

The first template is 'corporate environment management' where local government and SMEs develop a combined joint venture to implement environmental management systems in the participating organisations (von Malmborg 2003). This method utilises a joint venture agreement to develop a specific tool for sustainable development between the government and SME participants. An example of this template was the development of a Geographic Information System (GIS) that outlines regional land use in the Monroe 2020 project examined by Manring et al. (2003).

The second template is 'sustainable business development' where there is a joint venture between several companies and the local government to develop a new and ongoing business enterprise that can be found in some eco-tourism ventures (von Malmborg 2003). Again, in this model, a formal joint venture agreement is established between the government and SMEs but in contrast to the first template, it is to create an ongoing business enterprise where all members achieve benefit.

The formal joint ventures outlined in the above two templates can place limits on the knowledge sharing that occurs. In formal collaborations with industry, the relationship is defined by contractual boundaries that reduce the risk for the industry partners towards loss of competitive advantage (Mentzas et al. 2006; Mowery et al. 1996; Sun \& Scott 2005).These boundaries can reduce the potential for knowledge sharing and knowledge creation.

The third template is 'community development' aimed at the sustainable growth of the entire local and/or regional community. Projects in this template include the development of regional growth agreements or shared welfare strategies (von Malmborg 2003). In this partnership, SMEs have less participation in the development of the programmes and are utilised only to provide a service or support but generally do not make decisions. There is no formalised joint venture defining participation.

A fourth template is the Inter-Organisational Network (ION) that acts as a network of affiliates (Manring et al. 2003; Manring \& Pearsall 2006). Some characteristics of the ION template are shifting structures in an ad hoc alliance where members collaborate on projects based on their skill and expertise (Manring \& Moore 2006). There is no single 
leader. Different members take the leadership role of the group dependent on their expertise (Manring \& Pearsall 2006). IONs also involve multilevel interaction and knowledge sharing as described in section 2.1.

Due to the less formal approach to collaboration in templates three and four, there can be more scope for knowledge sharing as the defining boundaries found in the joint venture templates don't exist. However, the knowledge shared can be impacted by the political issues that affect government collaboration as outlined in section 2.2.

Each of these templates is focused on sustainability. However, both the "corporate environmental management' and the 'sustainable business development' templates also contain a high level of economic focus and structured approach to the relationship and the goal of the project undertaken. With the 'community development' and ION templates, the focus is more on the community and regional outcomes. Both also operate with less structure, having no joint venture agreement.

\subsection{The gaps}

The research on industry-government inter-organisational collaboration is growing but there are still a number of gaps particularly in the area of knowledge sharing.

As we have seen, inter-organisational groups may interact and share knowledge at different structural levels in their operations (Manring et al 2003; Manring \& Pearsall 2006; Sanders 2001). However, there is little discussion about how the knowledge at the different levels flows between the levels or influences the knowledge sharing at different levels. Additionally there needs to be more insight into how the different levels of interaction aids members in their knowledge sharing contribution.

There is evidence in the literature of the advantages when members can see the 'big picture' and access a broad knowledge domain through government-industry collaboration (Manring et al. 2003; Paquette \& Wiseman 2006; Tang 2008). However, the focus is on those benefits at the group level. There is also a need for further insights of how the mixed membership of these inter-organisational groups can contribute at the individual level in particular the personal network development for members through their association.

Lastly, there is little research around boundary spanning problems of communicating group knowledge to external organisations. There is much literature on boundary spanning with emphasis on the roles of knowledge brokers who aid in communicating knowledge to improve knowledge transfer and acceptance (Carlile 2004; Currie et al. 2007; Maaninen-Olsson et al. 2008; von Malmborg 2003). However, there is limited research on external boundary spanning with regards to the mix of industry and government external bodies particularly when dealing with the multiple agendas and translation of useful knowledge into relevant contexts.

Our research looks into these gaps of knowledge sharing by examining an interorganisational sustainable development group that involves a mix of government and industry members.

\section{Methodology}

This research is a case study based on an environmental inter-organisational group. The research question at the core of this study is how the knowledge sharing takes place in a 
Author

regional, sustainable development inter-organisational group. Specifically, we are interested in how the broad knowledge domain of the group influences knowledge sharing; how the knowledge sharing at different levels within the group occurs; and how the need to span boundaries between the group and external organisations impacts knowledge sharing.

This research was undertaken utilising multiple methods and included analysis of the knowledge networks formed within the group, examination of the group activities and of the individual's perceptions within the group. A mixed approach for study allowed for the collection of different data during the phases of the research and to develop a richer understanding of the knowledge sharing issues faced by mixed inter-organisational sustainable development groups. Additionally, the multiple methods for data collection and analysis allowed for validation of the results by being able to confirm or test results against the other sources (Mingers 2001).

\subsection{Case study background}

The case study focuses on an environmental group established in 2002 as a sub-group of a regional alliance between five municipal councils and a number of independent organisations in regional Australia. Based on documents provided by the group Chairman, the purpose of the alliance is:

- To develop a platform for the region to be able to communicate with all levels of government using one voice.

- Facilitate multi-agency collaboration and sharing of information and resources.

- To promote cross-border collaboration between the municipalities with a focus on 'big picture' regional issues.

The environmental sub-group is one of several sub-groups formed through the regional alliance which focus on areas such as regional economy, transport, health and wellbeing, and the environment.

The environmental group has approximately 30 members at this time. The membership includes representatives from the council and council officers of each local government municipality. There are also members from state government departments and agencies that have a focus on sustainable development including such organisations as the Department of Primary Industries, the Environmental Protection Agency and Sustainability Victoria. Additionally there are several members from industries and private citizens with experience in the field of sustainable development. The industry members are from SME organisations within the region.

The purpose of the environmental group is to "provide a forum for participating interest groups to discuss important regional environmental issues with a view to developing strategies and project plans to address them". The group runs according to an established 'terms of reference' which includes:

- Share information on current and planned programs so that synergies between them can be identified and promote collaborative approaches.

- Facilitate a common position on important regional environmental issues. 
- Support the creation of working groups to provide specific advice, deliver projects and undertake targeted activities.

Undertakings developed by the environmental group are presented to the Board of Directors by the environmental group's Chairman and the alliance CEO. These projects are then voted on by Board members to determine if they should be allocated a status of 'priority project'. Priority projects are then promoted by the Board of Directors to the State and Federal governments for future funding allocations. For the purpose of this study, the 'alliance' is considered one of the external bodies that the sustainable development group reports to.

Over a period of ten months we have observed the group's operational meetings. We have also completed nine interviews and 20 questionnaires including interviewing key members such as the group Chairman and the alliance CEO. Other interviewees have included representatives from local councils, government departments and SMEs.

The group was selected as the case study because it is a regional inter-organisational sustainable development group that has a structure similar to the ION template outlined in section 2.3. The group includes a mixed membership of government and enterprise and has a large scale regional sustainable development focus.

\subsection{Data collection}

Data was collected through three primary means: 1) questionnaire of the majority of group members to obtain an overall understanding of knowledge sharing within the group; 2) in-depth interviews from a sample of members to obtain deeper insights of why members participate in these sustainable development groups and what benefits they receive through participation; and 3) direct observations of group meetings to gain an understanding of the internal workings of the group and each member's roles. A more detailed explanation of the three methods follows.

The purpose of the preliminary questionnaire was to collect network data on who the members of the group feel are the experts on specific types of knowledge and who they talk to outside of the group. The questions utilised were adapted from research by Giuliani (2005) who used social network analysis to examine cluster knowledge networks developed by individual members of the clusters in the Italian and Chilean wine production industries. Similar to Guiliani's research, we wanted to examine who among the group are the most knowledgeable in different areas. The only changes to Giuliani's questions where to suit our sustainable development context and knowledge areas. This allowed us to develop a knowledge map on specific knowledge areas dealt within the group. From an initial analysis of group meeting agendas, four knowledge areas were identified: group operation matters; regional and sustainable development policies; practical applications leading to regional sustainable development; and funding related matters. The knowledge map was developed by asking questions such as:

Which members of the group have the most knowledge about issues of sustainable development policy?

Which members of the group have the most knowledge about sustainable development practical applications? 
Author

These questions aid in establishing the network of contacts members have developed with each other for informal sharing of knowledge on the main issues that they are dealing with in sustainable development.

To improve the accuracy of responses in the questionnaire, we utilised a free choice approach to the questions, allowing participants to name as many or as few as they wished (Wasserman \& Faust 1994). We also chose a rostered recall approach rather than free recall in the listing of names in the group (Wasserman \& Faust 1994). Participants were provided with a list of the group member's names to aid as a prompt to who was part of the group. As the case study has membership changes and not all members can attend every meeting, provision of a roster of names aided participants in naming the members they felt best suited to each question.

The in-depth interview utilised semi-structured, focused, questions to allow us to talk to individual members about the group and who they communicate with. The questions were adapted from Tang (2008) on knowledge sharing in inter-organisational collaborations in the biotech industry. Tang's questions looked at why members of the inter-organisational group would participate in knowledge sharing and what they received from that participation. These questions resonated with our research to understand why members would participate in inter-organisational sustainable development knowledge sharing, particularly industry member's that risk the loss of competitive advantage through participation. We adapted Tang's questions on why member's would collaborate and what they would discuss, adjusting them for our sustainable development context. The questions included:

What benefits does your organisation receive through membership with this group?

What does the group discuss or collaborate on and can you give examples?

For those you indicate have the most knowledge about sustainable development practical applications, what types of knowledge do you communicate to them, or they communicate to you?

These questions allowed us to see why an organisation has agreed to be a part of this knowledge sharing group as well as what the group actually discusses. Additionally we examined whether the participant communicated specifically on certain types of knowledge and whether that was done inside or outside group events.

Direct observation of group meetings allowed us to acquire knowledge on the patterns of social interaction in their natural environment (Henn et al. 2009). Specifically we were able to observe how the group communicates as a whole, the group structure, what knowledge was being shared and how the members interact. Through observation of the group meetings, we are able to build an understanding of the types of issues discussed within the group, the interactions between members and the projects undertaken. Additionally, direct observation can give a different perspective to what the participants themselves think may be happening. Observation also allowed us to develop a connection with members of the group and to build familiarity and trust that aided in carrying out the interviews.

A summation of the data collection methods can be seen in Table 1 showing their relation to the analysis method and purpose of enquiry. 


\subsection{Data analysis}

Data analysis involved social network analysis based on the questionnaire data complimented by content analysis of interview data and observational field notes. The main purpose of social network analysis is to examine the relationships between actors (Wasserman \& Faust 1994). One aspect is its use in determining the relational ties between actors as channels for transfer or 'flow' of resources, in this case the resource is knowledge. The questions specifically address the issue of who each member considers to be the most knowledgeable with regards to the specific knowledge type. Data collected was directional, indicating who members talk to rather than the assumption of reciprocal communication. Network maps were developed to analyse the interaction between members of the group at the personal network level. These network maps provided insights into which members of the group were most actively sought for their knowledge on sustainable development. Analytical tests such as centrality were utilised to see the prominence of members in the network. Members with a high centrality degree are in contact with many other actors within the network (Wasserman \& Faust 1994). Centrality can be further defined by directional relationships where indegree indicates that a member is approached by other members, and outdegree indicates the relationship where a member approaches other members. A high indegree indicates that these are members that are approached often by other actors within the network and are recognized as a major source of knowledge (Wasserman \& Faust 1994). Thus centrality analysis made it possible to highlight which members were most sought for their knowledge (indegree centrality) (Wasserman \& Faust 1994).

The interview instrument allowed us to do three things:

- Build up an understanding of why members seek out specific group members for discussion and sharing knowledge.

- Develop an understanding of how the group members share knowledge at the group and informal network levels.

- We also developed insight into the group structure, how the group operates and how it has evolved over time.

Microanalysis was applied to interview data in order to identify major themes, issues and concepts that shape knowledge sharing activities and relationships within the group (Strauss and Corbin 1998). Additionally data from individual interviews was crosschecked to verify the roles of key experts in the knowledge network.

As interview data can be individualistic and focused on the individual participant, the responses from the participants can be limited somewhat to their recall and their priorities (Kvale \& Brinkmann 2009). To understand how the group shares knowledge, to counter the possibility of not getting a full understanding of the issues discussed, we used observational data collected from group meetings. Field notes from observations were analysed to develop an understanding of synergies within the group and the member's interactions. We also utilised observational data to validate our findings from the interviews and social network analysis (Mingers 2001).

A summation of the data analysis methods in relation to the data collected and the purpose of enquiry can be found in Table 1 below.

Table 1 Summation of data collection and analysis techniques utilised 


\begin{tabular}{|c|c|c|c|}
\hline $\begin{array}{l}\text { Purpose of the } \\
\text { analysis }\end{array}$ & $\begin{array}{l}\text { Data collection } \\
\text { methods }\end{array}$ & Data analysis methods & $\begin{array}{c}\text { How the method was } \\
\text { used }\end{array}$ \\
\hline $\begin{array}{l}\text { Build up an } \\
\text { understanding of why } \\
\text { members seek out } \\
\text { specific group } \\
\text { members for } \\
\text { discussion and } \\
\text { sharing knowledge. }\end{array}$ & $\begin{array}{l}20 \text { questionnaires } \\
\text { Nine in-depth } \\
\text { interviews }\end{array}$ & $\begin{array}{l}\text { Social network analysis } \\
\text { Microanalysis of } \\
\text { Interview data }\end{array}$ & $\begin{array}{l}\text { Building network } \\
\text { maps, including } \\
\text { personal networks; } \\
\text { expertise networks; } \\
\text { map of reciprocal } \\
\text { communications } \\
\text { Coding for } \\
\text { members' } \\
\text { communications and } \\
\text { reflection on } \\
\text { expertise }\end{array}$ \\
\hline $\begin{array}{l}\text { Develop an } \\
\text { understanding of how } \\
\text { the group members } \\
\text { share knowledge at } \\
\text { the group and } \\
\text { informal network } \\
\text { levels. }\end{array}$ & $\begin{array}{l}20 \text { questionnaires } \\
\text { Nine in-depth } \\
\text { interviews } \\
\text { Ten months } \\
\text { observations of group } \\
\text { meetings }\end{array}$ & $\begin{array}{l}\text { Statistical analysis of } \\
\text { questionnaire data, } \\
\text { Microanalysis of } \\
\text { interview data and field } \\
\text { observations }\end{array}$ & $\begin{array}{l}\text { Mapping Group } \\
\text { demographics; } \\
\text { Coding for themes } \\
\text { and concepts which } \\
\text { shape knowledge } \\
\text { work of the group; } \\
\text { Mapping observed } \\
\text { knowledge sharing } \\
\text { processes and } \\
\text { activities; available } \\
\text { expertise; and KS } \\
\text { relationships }\end{array}$ \\
\hline $\begin{array}{l}\text { Develop insight into } \\
\text { the group structure, } \\
\text { how the group } \\
\text { operates and how it } \\
\text { has evolved over } \\
\text { time. }\end{array}$ & $\begin{array}{l}\text { Nine in-depth } \\
\text { interviews } \\
\text { Ten months } \\
\text { observations of group } \\
\text { meetings } \\
\text { Group documents }\end{array}$ & $\begin{array}{l}\text { Social network analysis } \\
\text { Microanalysis of } \\
\text { interview data and field } \\
\text { observations }\end{array}$ & $\begin{array}{l}\text { Building network } \\
\text { maps of personal } \\
\text { networks } \\
\text { Coding for themes } \\
\text { and concepts on } \\
\text { group interaction } \\
\text { Documenting a } \\
\text { timeline of group } \\
\text { development }\end{array}$ \\
\hline
\end{tabular}

\section{Examination of knowledge sharing in an inter-organisational network on regional sustainable development}

The purpose of this research was to examine how knowledge sharing occurs within a sustainable development group, how the broad knowledge domain of the group can influence knowledge sharing and how the need to span boundaries between the group and external organisations impacts knowledge sharing. This section outlines the results of this examination with a regional, inter-organisational sustainable development group case study. 


\subsection{Knowledge sharing in a multilevel group structure}

The group operates only according to a terms of reference and has no formal alliance to set the standards, type or depth of knowledge sharing between members. It operates across multiple levels similar to that described by Manring et al. (2003) and Manring and Pearsall (2006) and discussed in section 2.1.

We have identified knowledge sharing and interactions between group members at three levels (see Figure 1). The top level in effect consists of the entire group and their involvement at group meetings. Members participate as and when they can at this level but there is no obligation to attend or join in discussions at each meeting. While there is strong interest in participating at this group level, members do find that their participation in the bi-monthly meetings can be sporadic due to conflicts with other work commitments. The bi-monthly meetings have an average of 20 members in attendance. The discussion at these meetings is focused on keeping members up-to-date with recent or upcoming sustainable development events such as conferences and workshops, outlining changes in government policies and regulations in sustainable development, identification of new funding opportunities for sustainable development projects and news of what local government and industry projects have been undertaken by the member's organisations. However, due to increased pressure to develop practical and educative projects that can be promoted within the region for State and Federal government funding and the lack of time for in-depth discussions at the bi-monthly meetings, members have recently developed a middle level of operations.

The middle level consists of working groups focused on particular projects. There are currently five working groups that examine issues such as environmental leadership, climate change and natural resources and assets. Development of these projects is based on the decisions made at the top, group level. The group has identified a need to carry out further work on a particular project such as climate change and have then developed the working group to pursue that work in a more intensive manner than is provided at the group level. Members volunteer to participate in one or more of these working groups and the participation is based on the individual member's skills, interest in the project and their availability. The working groups consist of approximately 5-7 members from the group and they meet more regularly than the group's bi-monthly meetings. They provide the participating member's with an opportunity to discuss the issues in more depth and to develop business cases, project plans, implementation plans and/or grant applications.

At the lowest level are the informal knowledge networks that have been developed between members aided by the interactions of the members at the top, group level. These networks are developed by the individual member's through their participation in the group and the opportunity afforded to develop ties with the other members. The informal networks provide the members with opportunities to discuss issues related to the group and their own work outside of the group's regular meetings. 


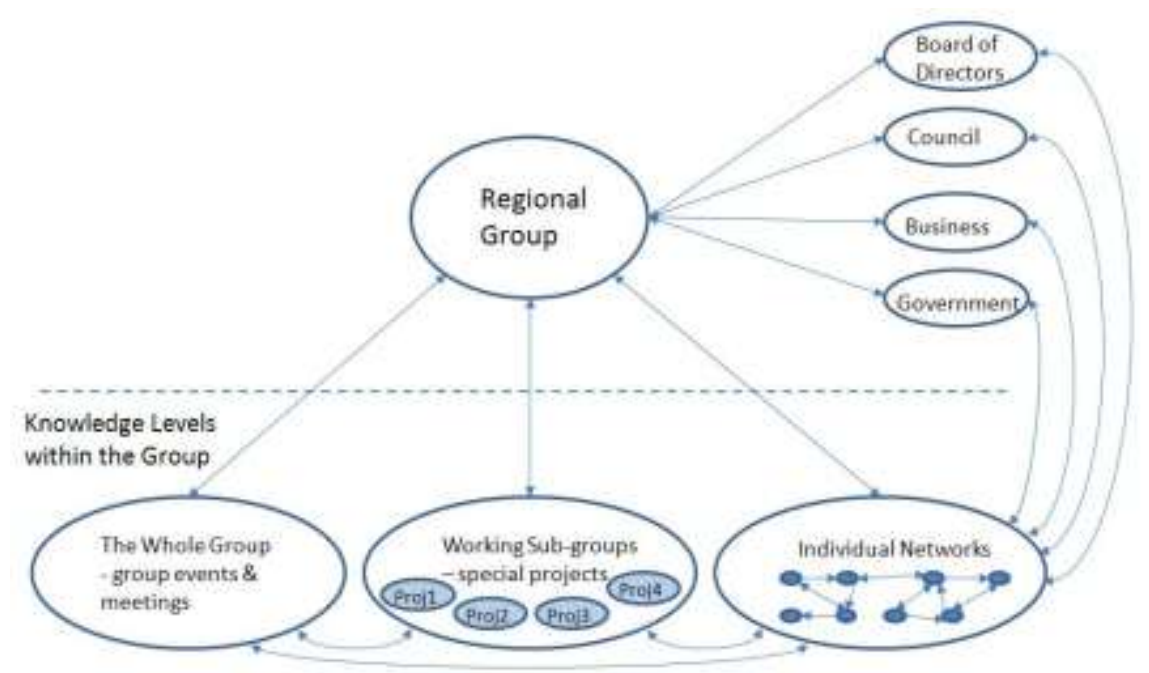

Figure 1 Knowledge flows across the multiple levels of group interaction

Knowledge sharing occurs at each of these levels within the group, but also flows through the levels (see Figure 1). At the group level, knowledge exchanged is often highlevel based on pre-determined agenda items. The group level meetings allow members to catch-up on the developments from the mid-level working groups and also to develop a broad level understanding of the issues as they affect the region. As described by one member "...it will enable thinking to come back to the broader group".

The interaction at the group level has triggered the development of the mid-level projects. For example, the group understanding of the importance of sustainable development within the region has led to the development of the 2050 scenario project that was carried out by the mid-level working group on future directions. Members can "...learn through the (group) that a project is occurring, where we can get together to discuss those projects in more detail". Additionally, members involved in working groups may utilise their informal networks to gather specific knowledge or to test responses to decisions made in the working group. For example, with the 2050 scenario project, the project needed to meet the regional sustainable development needs but also the political requirements of the local government municipal councils, because "If we came up with a scenario that any of the municipalities objected to, it would never see the light of day."

At the informal network level, the knowledge sharing is more specific to the member's job roles and work places but it also occurs more spontaneously than is available at the group level. Members described the informal network knowledge sharing as "...spontaneous...getting information that you're unaware of that can help you to do better work" and as an opportunity to ask "...nitty-gritty type questions". However, this informal network knowledge can filter into the mid-level working groups and also into the top level, group interactions as members build their mutual understanding of the regional aspects of sustainable development.

This multilevel structure has provided advantages in allowing members to participate and contribute knowledge to the group through the differing levels even if a member may not always be available for group activities at all three levels due to work conflicts. 
Through analysis of our observational field notes, we identified members of the group that never attended meetings. However from the knowledge network data collected through the questionnaire and confirmed through interviews, members identified one of these 'non-active' members, designated TH highlighted in Figure 2, as a key node in their personal knowledge networks indicating regular contact with them outside of the group meetings in areas such as sustainable development policies and practical knowledge.

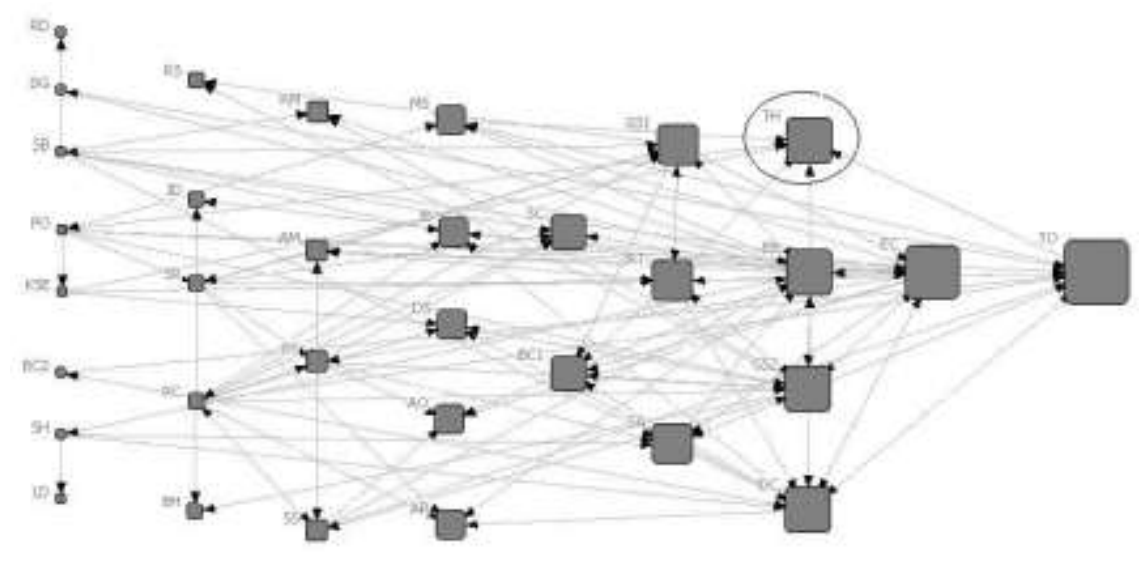

Figure 2 Network map showing the high indegree centrality of member TH at the informal network level. Network map is ordered from left to right in increasing indegree centrality.

As can be seen from Figure 2, member TH (circled) is in the third highest level of indegree centrality in the network map. While member TH is unable to attend the group meetings regularly due to other work commitments, the multiple levels of interaction allow TH to continue to share their knowledge with group members at the informal network level.

We can see that the knowledge sharing occurs over multiple levels as indicated in the ION template (Manring et al. 2003) outlined in section 2.3. However, what we also see is that the knowledge flows between the levels informing and directing activities at the three levels. This is evident from the formation of the working groups at the middle level due to identification of the need for more specific knowledge sharing on particular projects, the use of informal network knowledge to test ideas developed in the working groups and the provision of working group knowledge at the group level to keep members informed on progress. This shows that the group's knowledge sharing is not restricted to particular levels of interaction but instead is dynamic influencing and building the knowledge shared and developed at other levels.

This multi-level interaction also allows for flexibility in the group's operations and knowledge sharing, adapting to the changing needs of members. The absence of formal arrangements for participation has allowed members to continue to participate and share knowledge at other levels within the group's operational structure when one level is not available to them. By allowing opportunities to participate at other levels, the group's multi-level structure has provided member's with flexibility for their interactions and knowledge sharing. This provides the group with the ability to retain valuable knowledge sources that otherwise might no longer be available to them. 
Author

\subsection{Broad knowledge domain}

Due to its regional focus and the inclusion of five municipal councils, this group has a broad knowledge domain that includes economic, social and environmental aspects but also has to consider urban, agricultural, industry and natural environment issues within the region such as water, wildlife and national parks. The mixed membership provides the group with knowledge and experience in these different issues. Members are able to build their knowledge and understanding of the effects and issues of sustainability beyond their working environment.

The group membership has altered over time with increasing membership and with new representative's joining the group as previous representative's move on to other positions. For some organisations, time constraints mean that attendance at group events is rotated through several personnel.

This evolving membership has provided new members with an interesting dichotomy in terms of knowledge sharing. New members joining the group have a steep learning curve to develop the mutual understanding of the group's broad knowledge domain that the long term members share. At the same time, their involvement in the group accelerates the development of their own personal knowledge networks. One member described the opportunity as, "without the (group)...it would've taken five years for me to get around all those agencies, probably, and make those contacts," and "being able to attend the (group) meetings, within months, you've got a good understanding of who's who and what agencies operate within the region."

This opportunity for rapid network development means that members are able to access this broad knowledge domain from the group's mixed membership for their personal work and in development of their mutual understanding of the group's perspectives. Member's are able to develop contacts and knowledge resources through their personal network but can also begin contributing knowledge through their personal networks and this knowledge eventually distils through the entire group.

\subsection{Sharing knowledge between the group and external organisations}

Any inter-organisational group working together must at some time return knowledge that they have developed, justifying their efforts, to the parent organisations that provide support and to other reporting authorities. As discussed in section 2.2, interorganisational groups, particularly those that involve government agencies, have complexities related to the political issues and multiple stakeholders involved. Secondly, not all the knowledge shared within the group necessarily needs to be communicated to the external organisations and inter-organisational groups need to develop some method of filtering and translating the knowledge that is shared beyond the group's boundary.

As can be seen from Figure 1, the group shares knowledge they develop with a number of organisations that are external though not independent of the group as the group members come from these organisations such as the local government councils, the alliance Board of Directors, government departments and regional businesses.

One of the issues raised through our interviews was the difficulty with getting buy-in from the organisations that make up the alliance and support the environmental groups operations. This buy-in is particularly important with the Board of Directors and local government councils that form the basis of the alliance and the environmental group “...because it's no use putting up something...that's at odds with what the council's 
doing...and same with the government departments". This has meant that when conveying knowledge about the environmental group's policy development or projects, they need to translate it so that is conveyed in a format that ensure acceptance. Some members of the group thus act as gatekeepers or knowledge brokers of the knowledge dispersed by the group, for example "...the politics of the Board are quite different to the politics of the (group) and so the manner in what I tell the Board and when I tell them needs to be sensitively handled". These gatekeepers also fill a role in developing knowledge for the group on what the agendas and perspectives are because "...you need to know what the government's agenda is so you can cast your submission." The role of gatekeeper by some members of the group has been emergent based on their connections and knowledge of the external organisations the group reports to.

Additionally, not all knowledge shared within the group needs to be released to the external organisations. The inter-organisational group has developed filters for the knowledge sharing beyond the group. Using their knowledge of the external organisations agendas and perspectives, the gatekeepers advise or aid in the development of the group's knowledge presentations to ensure that the knowledge can be accepted and not "...scare the pants off some of the board members."

An intrinsic benefit of the group's development has been the spanning of sustainable development knowledge and issues across local government boundaries that have led to a reduction in "boundary dependent isolated decision making" within the region as one of the group members stated. The formation of the group with membership that includes external organisations such as the local government councils has meant that the group often provides the one opportunity where many of these organisations are located in the same room. For example, a recent project of the group involved the release of catchment water into an ailing river system. This project involved the local government councils that the river system transgressed and the local water authority, catchment authority and a number of State government departments. The group provided opportunity for the members representing these organisations to share knowledge on the state of the river system and to negotiate the adaption of agendas to develop a pragmatic solution. As outlined to the group member's at one of the observed bi-monthly meetings, the resulting decision has meant that a regular release of catchment water now maintains the river system allowing for the development of local biodiversity.

This filtering of knowledge and adaptation to suit reporting to external organisations and understanding that not all knowledge should be communicated is reflective of the semantic and pragmatic boundary crossing required in knowledge sharing as outlined by Carlile (2004). We can see that knowledge developed within the group cannot just be dispersed to the external organisations as is, but must be transformed and conveyed in a manner that allows for the groups knowledge to be heard and accepted. Additionally, some members of the group take on the responsibility of ensuring that the group as a whole understands the political agenda's of the Board of Directors, local government councils and government departments that comprise some of the alliance membership.

The use of sustainable development groups can also facilitate knowledge sharing across organisational boundaries such as those between local government councils. There is evidence through membership with this sustainable development group that participation brings opportunities to share sustainable development knowledge and issues across the boundaries between local government councils and government departments. This facilitation has resulted in a reduction of isolated decision making and opportunities for pragmatic, regional solutions to sustainable development issues that affect the 
external organisations that are a part of the group. These issues also highlight the complexities the group faces by working with multiple stakeholders that can have varying and possibly even conflicting agendas.

\section{Conclusions}

Our research centred on a regional sustainable development group operating without the formal hierarchical requirements of business or government inter-organisational relationships.

Our first research question was to understand how knowledge sharing occurs within these inter-organisational sustainable development groups. Through the literature, we had identified that these types of groups do operate at multiple levels (Manring et al. 2003) but there was no understanding of what and how the knowledge from within each level influenced or contributed to the knowledge sharing at the other levels. We have found that the knowledge sharing within this sustainable development group is dynamic and flows between the levels. The knowledge shared at the top group level can influence not only the development of middle level working groups but also the projects undertaken within those groups. Knowledge from the lower informal networks is utilised to test the development of ideas through knowledge sharing at the working groups. The group maintains a cohesive understanding of all the knowledge shared by having the working groups report back to all the members at the top level to keep everyone apprised of progress and the knowledge that has been developed.

Additionally as part of understanding how knowledge sharing occurs within this sustainable development group, we identified that the flexibility of their operational structure utilising multiple levels has meant that the group has been able to retain access to participant's knowledge even when that participant cannot effectively operate at the top level with the group. Instead, member's who cannot participate at the group's bimonthly meetings can still share their knowledge and expertise through the informal network. This flexibility has allowed this sustainable development group to retain valuable knowledge sources that otherwise may have been lost to the group.

We also aimed to examine how the broad domain of knowledge within these mixed membership group's influenced the knowledge sharing particularly at the personal network level. We have found that while the extensive membership means that members have a steep learning curve to develop a mutual understanding necessary for successful group knowledge sharing (Carlile 2004; Cohen \& Levinthal 1990; Lawson et al. 2009), the benefit of this mixed membership is in the ability for members to rapidly develop their own personal networks and access to this broad knowledge domain. The participation in this group of mixed membership has meant that members can develop contacts and knowledge resources with the other member's more quickly than they would through normal work interaction. This provides the members with a broad knowledge domain that they can access for their own work and to develop their mutual understanding of the regional sustainable development issues through the group activities that facilitate meeting others within the regional field.

Thirdly, we examined this regional sustainable development group to understand the impact of boundary spanning between the group and the external organisations has on knowledge sharing. The differing agendas of the external organisations do add complexity when attempting to share knowledge outside of the group boundaries as the 
Title

knowledge shared needs to be communicated in ways that improves external acceptance. This group has mitigated these issues by utilising gatekeepers. These gatekeepers use their skills and experience with the external organisations so that knowledge shared is translated and or filtered to ensure acceptance of proposed projects. Thus they play a wider role than that of knowledge brokers defined in the literature that act to put the relevant parties in contact but do not contribute to the knowledge sharing (Rowe \& Enticott 1998; von Malmborg 2003). Additionally, participation within the group by the external organisations facilitates opportunities to share knowledge and issues across the boundaries. Participation has allowed these members to examine sustainable development issues that extend beyond their own organisation such as issues that cross local government boundaries. The group has provided the opportunity to bring the relevant stakeholders together in one place where they share knowledge of issues and negotiate pragmatic solutions and reduce boundary dependent, isolated decision making.

This research is an early stage in a larger study on regional sustainable development groups and as such has only focused on one case study. The use of a single case study design does present limitations with regards to generalisation of the results of the study. However, when exploring a research idea with limited previous study, the use of a single case study has provided opportunity for more in-depth understanding of the phenomenon. Further research is currently being undertaken to examine other regional sustainable development groups. These further cases provide opportunity to compare findings from this case study and develop a more generalised perspective of knowledge sharing in these groups. Additionally, research is being undertaken to examine the uses of external knowledge sources within the group.

While further research is required to develop generalisations with regards to knowledge sharing in a government-industry collaboration, the initial research has been informative in providing greater insights into the multi-level structure of knowledge sharing in inter-organisational groups and the role of gatekeepers and filters to aid in sharing knowledge beyond group boundaries. These insights highlight once again an importance of such groups in facilitating dialogue between industry and government organisations in regard to the matters with complex and ambiguous knowledge, such as regional sustainable development.

\section{References}

Carlile, P.R. (2004) Transferring, translating, and transforming: An integrative framework for managing knowledge across boundaries, Organization Science, 15 (5), 555-568

Cohen, W.M. and Levinthal, D.A. (1990) Absorptive capacity: A new perspective on learning and innovation, Administrative Science Quarterly, 35 (1), 128-152

Currie, G., Finn, R. and Martin, G. (2007) Spanning boundaries in pursuit of effective knowledge sharing within networks in the NHS, Journal of Health Organization and Management, 21 (4/5), 406-417

Giuliani, E. (2005) The structure of cluster knowledge networks: uneven and selective, not pervasive and collective, DRUID Working Paper 2005-11, http://www.druid.dk

Grabher, G (2003) The Project Ecology of Advertising: Tasks, Talents and Teams, in Innovations, Regiona and Projects: Studies in new forms of knowledge governance, eds Bjorn Terje Asheim and Age Mariussen, Stockholm: Nordregio 2003 
Author

Gravier, M.J., Randall, W.S. and Strutton, D. (2008) Investigating the role of knowledge in alliance performance, Journal of Knowledge Management, 12 (4), 117-130

Hartley, J. and Benington, J. (2006) Copy and paste, or graft and transplant? Knowledge sharing through inter-organizational networks, Public Money and Management, April, 101-108

Heiman, B.A. and Nickerson, J. (2004) Empirical evidence regarding the tension between knowledge sharing and knowledge expropriation in collaborations, Managerial and Decision Economics, 25, 401-420

Henn, M., Weinstein, M. and Foard, N. (2009) A Critical Introduction to Social Research. $2^{\text {nd }}$ Edition, SAGE Publications, London

Kvale, S. and Brinkmann, S. (2009) Interviews: Learning the Craft of Qualitative Research Interviewing. $2^{\text {nd }}$ Edition. SAGE Publications, California

Lawson, B., Petersen, K.J., Cousins, P.D. and Handfield, R.B. (2009) Knowledge sharing in interorganizational product development teams: The effect of formal and informal socialization mechanisms, The Journal of Product Innovation Management, 26, 156-172

Levy, M. Loebbecke, C. and Powell, P. (2003) SMEs, co-opetition and knowledge sharing: The role of information systems, European Journal of Information Systems, 12, 3-17

Lindkvist, L. (2005) Knowledge Communities and Knowledge Collectivities: A Typology of Knowledge Work in Groups, Journal of Management Studies 42:6 September 2005,

Maaninen-Olsson, E., Wismén, M. and Carlsson, S.A. (2008) Permanent and temporary work practices: Knowledge integration and the meaning of boundary activities, Knowledge Management Research \& Practice, 6, 260-273

Manring, S.L. and Moore, S.B. (2006) Creating and managing a virtual inter-organizational learning network for greener production: A conceptual model and case study, Journal of Cleaner Production, 14, 891-899

Manring, S.L. and Pearsall, S. (2006) Creating an adaptive ecosystem management network among stakeholders of the lower Roanoke river, North Carolina, USA, Ecology and Society, 10 (2), 16 online

Manring, S.L., Rivkin, G.W. and Rivkin, M.D. (2003) The application of network and learning organization models to improve ecosystems management: Monroe 2020 case study, Environmental Practice, 5 (2), 119-133

Martinuzzi, A., Huchler, E. and Obermayr, B. (2000) EcoProfit: Promoting partnerships between small and medium sized enterprises and local authorities, Greener Management International, 30, 83-96

Mentzas, G., Apostolou, D., Kafentzis, K. and Georgolios, P. (2006) Inter-organizational networks for knowledge sharing and trading, Journal of Information Technology Management, 7, 259276

Mingers, J., (2001) Combining IS research methods: Towards a pluralist methodology, Information Systems Research, 12 (3), 240-259

Mowery, D.C., Oxley, J.E. and Silverman, B.S. (1996) Strategic alliances and interfirm knowledge transfer, Strategic Management Journal, 17, 77-91

Paquette, S. and Wiseman, E. (2006) Knowledge for sustainable development: The role of knowledge networks \& organizational learning. In Proceedings of the Americas Conference on Information Systems, 1706-1713

Rowe, J. and Enticott, R. (1998) The role of local authorities in improving the environmental managements SMEs: Some observations from partnership programmes in the west of England, Eco-Management and Auditing, 5, 75-87

Sanders, W.H. (2001) The Great Lakes Forest Alliance, Journal of Sustainable Forestry, 13 (1), 223-236 
Title

Sedlacek, S. and Gaube, V. (2010) Regions on their way to sustainability: The role of institutions in fostering sustainable development at the regional level, Environment, Development and Sustainability, 12, 117-134

Shearlock, C., James, P. and Phillips, J. (2000) Regional sustainable development: Are the new regional development agencies armed with the information they require? Sustainable Development, $8,79-88$

Strauss, A.L., and Corbin, J. (1998) Basics of Qualitative Research: Techniques and procedures for developing Grounded Theory, $2^{\text {nd }}$ Edition, SAGE Publications, Thousand Oaks

Sun, P. Y-T. and Scott J.L. (2005) An investigation of barriers to knowledge transfer, Journal of Knowledge Management, 9 (2), 75-90

Tang, L. (2008) Informal interorganizational knowledge sharing: The case of the biotechnology industry. In the $94^{\text {th }}$ Annual Conference of the National Communication Association, San Diego

van den Hooff, B., Elving, W., Meeuwsen, J.M. and Dumoulin, C. (2003) Knowledge sharing in knowledge communities, In Communities and Technologies (Huysmen, M.H., Wulf, V. \& Wenger, E. Eds), Kluwer Academic Publishers, Deventer

von Malmborg, F. (2003) Conditions for regional public-private partnerships for sustainable development - Swedish perspectives, European Environment, 13, 133-149

Wagner, S.M. and Bukó, C. (2005) An empirical investigation of knowledge-sharing in networks, The Journal of Supply Chain Management, Fall, 17-31

Wasserman, S. and Faust, K. (1995) Social Network Analysis: Methods and Applications, Cambridge University Press, USA 